Estudios deDerecho

Fundada en 1912
UNIVERSIDAD DE ANTIOQUIA 


\title{
Sistema penal y revolución de las sociedades de control: suplicio, prisión e inocuización. Desde la sociedad de control al control de la sociedad*
}

\section{Manuel L. Ruiz-Morales*}

\section{Resumen}

El artículo analiza la evolución del castigo a lo largo de la historia, pasando de una primacía en la utilización de las penas corporales a la utilización masiva de la pena de prisión -que continúa siendo la principal sanción penal de los sistemas de penas en los ordenamientos penales del mundo-. Sin embargo, la propia prisión se fue transformando de acuerdo a las necesidades que debía cumplir como centro de reclusión, convirtiéndose en el paradigma más palmario de sociedad de control. A partir de ahí la institución penitenciaria se bifurcó en dos vías diversas, las cuales verdaderamente convergen en sí, puesto que el ordenamiento penal actual es esclavo del orden y el control, lo que terminado instaurando la inocuización de los individuos, tanto en los establecimientos penales, como en la propia sociedad.

Palabras clave: prisión; penas corporales; inocuización; sociedades de control; castigo.

\section{Criminal system and revolution of control agencies: supply, prison, and innocuousness. From control agencies to social control}

\begin{abstract}
The article analyzes the evolution of punishment throughout history, going from primacy in the use of corporal punishment to the massive use of prison sentence -which continues to be the primary criminal sanction of penalty systems in the penal systems of the world-. However, the prison itself was transformed according to the needs that it had to fulfill as a detention center, becoming the most apparent paradigm of a control society. From there, the penitentiary institution branched out into two different pathways, which truly converge in themselves, since the current criminal Law is a slave to order and control, which ended up establishing the innocuousness of individuals, both in penal establishments, as well as in society itself.

Keywords: prison; corporal punishment; innocuousness; control societies; punishment.

\section{Sistema penal e revolução das sociedades de controle: suplício, prisão, inoculação. Desde a sociedade de controle ao controle da sociedade}

\section{Resumo}

O artigo analisa a evolução do castigo ao longo da história, passando de uma primazia na utilização das penalizações corporais ao uso massivo da pena de prisão, - que continua sendo a principal sansão penal dos sistemas de penas nos ordenamentos penais do mundo-. Porém, a própria prisão tem sido transformada de acordo com as necessidades que devia cumprir como centro de carceragem, transformando-se no paradigma mais evidente da sociedade de controle. A partir daí, a instituição penitenciária bifurcou-se em dois caminhos diversos, os quais verdadeiramente convergem entre si, já que o ordenamento penal atual é escravo da ordem e do controle, o que termina instaurando a inoculação dos indivíduos, tanto nos estabelecimentos penitenciários como na própria sociedade. Palavras-chave: prisão; penas corporais; inoculação; sociedades de controle; castigo.

1 Artículo de reflexión. Grupo de investigación: SEJ 378, Sistema penal y criminalidad.

2 Personal docente investigador en Universidad de Cádiz, España, la cual es la filiación. Investigador invitado en el Instituto de investigaciones jurídicas y sociológicas Ambrosio Lucas Gioja de la Facultad de Derecho de la Universidad de Buenos Aires. Correo electrónico: Manuel.ruizmoral@uca.es ORCID: 0000-0003-2381-1503 


\section{Sistema penal y revolución de las sociedades de control: suplicio, prisión e inocuización. Desde la sociedad de control al control de la sociedad}

\section{Introducción}

Las denominadas sociedades de control no son algo nuevo, toda vez que desde el principio de los tiempos el ser humano se ha sentido desprotegido, de ahí que los antepasados biológicos de la especie humana -homo sapiens-, desde los primeros australopitecos hasta el hombre de neandertal se agrupasen en pequeñas sociedades de una decena de miembros -aunque a veces se estructuraban en comunidades más grandes-, al efecto de procurarse seguridad, protección y el necesario alimento entre los miembros del grupo, en función de la división de tareas y en un apoyo social significativo ${ }^{1}$ (De J., 2017; Nieves, 2014).

De esta manera, aparecieron patrones de comportamiento que reglaban las conductas de los individuos que estas primigenias comunidades habitaban, lo que fue normalizando la vida en el seno de ellas, a través de estas prácticas, hábitos y costumbres en un determinado sentido.

Es decir, a medida que la sociedad comienza a progresar, la comunidad -aunque primitiva y de escasa dimensión- establece modos de control de las conductas de sus miembros -al estilo del control social ejercido actualmente por la familia ${ }^{2}$, como medios de control social de carácter informal ${ }^{3}$, con el objetivo de mantener el orden en dicho clan.

No obstante, aún en esos momentos de la evolución, las nociones de justicia, de la moral, de lo que está bien o mal, apenas estaban desarrolladas, por lo que los sujetos podían actuar conforme a su parecer o sus apetencias. Así, ante el ataque

1 No debe extrañar tal afirmación, ya que la mayoría de animales conforman grupos de ellos. En este sentido, los primates además de conformar grupos, exhiben normalmente cierta organización social.

2 En la actualidad, juega un papel fundamental la educación, atendiendo a la madurez de los menores (Vega Fernández, 2017, p. 174).

3 También denominado difuso (Malo Camacho, 2001, p. 22). 
-no permitido consuetudinariamente- de un miembro de la tribu la forma de hacer justicia fue primeramente la autotutela individual y privada, al efecto de defender la propia vida o la de los miembros de ese grupo.

Esto es, se trata del momento conceptual al que los pensadores y teóricos del Estado -principalmente del Renacimiento y de la Ilustración- denominaron "estado de naturaleza", ya que el hombre prehistórico podía perseguir sus deseos sin limitación alguna, toda vez que el individuo en ese estado inicial tenía derecho a todo -incluso a servirse del cuerpo de los otros iguales- para satisfacer sus apetitos, al no existir tampoco conceptos como el de criminalidad. Esta situación de constante inseguridad, intranquilidad y miedo, era como una especie de guerra de todos contra todos, en la que el débil solo podía aprovechar oportunidades de defensa basadas en la venganza o en el aprovechamiento de la distracción del más fuerte (Ginzburg, 2015, p. 33; Ramírez, 2011, pp. 22-25).

Posteriormente, cuando el desarrollo social alcanzó una intensidad mayor, surgió un modo más avanzado de solucionar los conflictos sociales, dejándose de lado la autotutela, y apareciendo la autocomposición. Esta modalidad de solventar conflictos, consistía en arreglar el asunto entre ambos contendientes (Moreno Catena y Cortés Domínguez, 2017, pp. 39-40), con la finalidad de restaurar la armonía y la concordia en el grupo social que permitiera vivir nuevamente con tranquilidad.

No obstante, la evolución respecto de los modos de resolver disputas jurídicas se produjo cuando los individuos optaron ${ }^{4}$ por someterse a la voluntad de un tercero -que sería el que decidía y dilucidaría la cuestión-, imponiendo una solución, en virtud de su posición superior a las partes en conflicto -heterocomposición(Moreno Catena y Cortés Domínguez, 2017, p. 42).

Así fue como funcionaron las primeras civilizaciones, la Sumeria en la Baja Mesopotamia, la del Antiguo Egipto, Grecia o Roma, ya que desde el Código de Hammurabi ${ }^{5}$-hace unos cuatro mil años- se utilizó la heterocomposición a la hora de resolver conflictos jurídicos, de ahí que se aludiera a la figura del juez -al poder estatal-, aun cuando a la hora de resolver disputas jurídicas se basase idealmente en la Ley del Talión (Franco, 1962, p. 333-335).

Y es que no se debe olvidar que ante la inseguridad que suponía el estado de naturaleza inicial, el hombre se unió para conseguir un determinado bien ${ }^{6}$ (RuizMorales 2018a, p. 318). En un sentido similar, argumentó Maquiavelo al entender

4 Optaron en el sentido hobbesiano o rousseauniano de sumisión voluntaria al poder por medio del contrato social, aunque es discutible si desde los primeros imperios, babilónicos, persas, griegos, romanos, se sometieron al sistema feudal, estos mecanismos se impusieron a los individuos.

5 Este código de leyes también empezó a normalizar y sancionar conductas, esto es, tipificar delitos, por lo que es el momento en el que comienza a desarrollarse un control social de carácter formal.

6 Según las teorías aristotélicas. 
que el individuo se agrupó para obtener una protección mayor, recayendo la jefatura tribal en el sujeto más robusto y valiente, para favorecer la defensa del colectivo. No obstante, la vida grupal mostró las conductas virtuosas y perjudiciales para el clan, instaurándose normas conductuales y sanciones, lo que situó en el mando de dicha sociedad al más justo en sus decisiones, en vez del más corpulento (Todarello, 2008, pp. 38-39) -sobre la base de la heterocomposición-. Finalmente, la corriente contractualista que surgió en el Renacimiento elaboró la teoría del pacto o del contrato social -para explicar la situación política en la que se hallaban- en virtud de la cual los individuos renunciaban a parte de sus derechos y libertades a cambio de gozar de tranquilidad para desarrollar su vida en sociedad ${ }^{7}$.

\section{El ambiente punitivo desde la Antigüedad a la época preilustrada}

Como reminiscencia de las soluciones al conflicto impuestas en las sociedades primitivas de corte tribal en las que primaba la venganza, durante más de tres mil quinientos años se castigó primordialmente mediante el uso de penas corporales, que fue la principal sanción utilizada durante la Antigüedad y durante toda la Edad Media (Zambrana Moral, 2005, p. 201).

Igualmente, esta retribución penal satisfecha en el propio cuerpo del delincuente, se extendió por todo el orbe. Tanto es así, que en el primitivo derecho penal chino, en el derecho persa (Jiménez de Asúa, 1957, pp. 268-269), en el anteriormente citado Código de Hammurabi, en el libro indio de Manú o en normas romanas -como las Doce Tablas o la Compilación Justinianea-, se contenían penas corporales como castigos (Zambrana Moral, 2005, p. 202).

Ahora bien, en el derecho penal de los pueblos germánicos alcanzó un papel preponderante la pena de muerte, dado que que muchas de las conductas que se castigaban anteriormente sobre el cuerpo del sujeto delincuente, se reprimieron durante la Edad Media con la pena capital (Lalinde Abadía, 1992, p. 1025). Ante tal situación, no es de extrañar que hasta el siglo XVIII se dijera que "el repertorio de las penas legales era muy escaso en cuanto a las leves y muy amplio respecto a las de mayor dureza". Además, la pena de muerte "era muy frecuentemente establecida, a fin de aterrorizar eficazmente a los ciudadanos, reservando las formas más dolorosas para los delitos más graves (Tomás y Valiente, 1973, p. 185) ${ }^{8 ”}$. A mayor abundamiento, ocurría que

7 A partir de dicho contrato social cada autor se decantaba por un sistema político diverso, desde los autoritarios Hobbes-, a los más liberales -Rousseau- pero que -en definitiva- servían para controlar a la sociedad, posibilitando la vida social y el mantenimiento del orden y la paz social.

8 Las penas corporales adquirieron principalmente dos formas, a saber: de mutilación -castración, vaciado de la cuenca de los ojos, amputación de miembros y extirpación de la lengua- y de azotes (Zambrana Moral 2010, pp. 6-12). 
La gran cantidad de delitos castigados con la pena de muerte eliminaba toda posible proporcionalidad entre delitos y penas. [...] Además, la pena era principalmente el castigo merecido por el delincuente, y su imposición tenía muchos visos de una Justa Venganza, siendo utilizada por el legislador como arma represiva. (Tomás y Valiente, 1973, pp. 186-187)

La pena consistía entonces en el suplicio del condenado -en el ensañamiento-, ya que el dolor era el elemento preponderante del castigo. De este modo, el linchamiento de carácter público servía para demostrar y restituir el poder superior del soberano, ya que -mediante el delito- el derecho dado por el princeps había quedado ultrajado. Ocurría además que el monarca gozaba de derecho a castigar los delitos, en virtud de aquella potestad del soberano a hacer la guerra a sus enemigos, que le permitía disponer -conforme a la ley- de la vida o muerte de sus súbditos (Foucault, 1990, pp. 53-54 y p. 62). Así, incluso monteria (1828) afirmó tal derecho a castigar, con base en pretensiones de mantener un espacio de seguridad y libertad para el desarrollo vital de la sociedad que el soberano gobernaba -conforme a la cesión de las parcelas de libertad resultado del contrato social-, pero afirmando su "necesidad" (Beccaria, 1828, pp. 9-11).

Por tanto, el control social ejercido mediante el derecho penal medieval -incluso moderno- se caracterizó por usar la amenaza y el miedo al dolor en contra del individuo, apareciendo el sufrimiento -o la propia eliminación del victimariocomo un mecanismo disuasorio de actividad delictiva alguna.

Ante tal situación, no debe extrañar que hasta la Ilustración -tanto durante la Antigüedad como durante el Medievo- la cárcel o prisión actuó no como pena, sino simplemente como un medio de retención o aprehensión ${ }^{9}$ que permitía el aseguramiento del delincuente mientras devenía su condena ${ }^{10}$, que -en todo casoconsistía en una pena sobre el cuerpo del reo -ya se tratara de torturas, suplicios o la muerte del delincuente ${ }^{11}$.

No obstante, durante el siglo XVI aparecen por diversos lugares de Europa algunos establecimientos que sirvieron para el internamiento, la reclusión y la corrección de grupos de población denigrados, tales como sujetos que vivían en la mendicidad o ejerciendo la prostitución. Uno de los más conocidos, era la Casa de Corrección "Rasphuis" en Ámsterdam fundada en 1596. Ahora bien, no sería hasta 1704 cuando se construiría el primer establecimiento ideado para privar a los individuos de libertad. Se trató de la Casa de Corrección de San Miguel en Roma, cuyo edificio se concibió

9 Las condiciones higiénicas del lugar eran indiferentes, y cualquier lugar que evitase la fuga del presumible autor del hecho se consideraba idóneo para acometer en él dicha retención. De ahí que lugares como la Torre de Londres, el castillo de Vincennes, o La Bastilla sirvieran como prisión en algún momento de su historia.

10 Al modo actual de la prisión preventiva.

11 Incluso se seguía castigando el cuerpo tras producirse el fatal desenlace. 
con tal finalidad, atendiendo a unas mínimas exigencias de salubridad para llevar a cabo la reclusión. Sin embargo, se debe advertir que este establecimiento servía para cumplir la penitencia impuesta a los clérigos que hubieran desobedecido las normas eclesiásticas, facilitando así su arrepentimiento (Cuello Calón, 1968, p. 302).

\section{Los fundamentos de la Ilustración en materia penal}

Los pensadores de la Ilustración, en la línea filosófica-política de crítica hacia el absolutismo, observaron en el ámbito del castigo que las prácticas sancionadoras que se venían desarrollando a la hora de hacer justicia, eran una simple consecuencia y una demostración más del absolutismo político de la época, lo que provocaba que el monarca actuase discrecionalmente y -en no pocas ocasiones- de manera excesiva a la hora de ejecutar los castigos, como demostración de ese poder supremo y divino del que estaba investido.

Por ello, los ilustrados entendieron que se debía de castigar de una mejor manera, sin excentricidades, sin esas notas de teatralidad, por lo que se dejó de atacar el cuerpo del delincuente -de una manera física-, ya que únicamente el cuerpo tenía que ser utilizado como instrumento de la pena (Foucault, 1990, pp. 17-19 y p. 86).

Entre las medidas ideadas por aquel entonces, se pueden mencionar la instauración del principio de legalidad o el establecimiento de un Tribunal impersonal -especie de Tribunal del Jurado "ad hoc" (Montesquieu, 1972, pp. 53-54 y p. 152), los principios de proporcionalidad de las penas y de objetividad, toda vez que la sanción penal debía de ser mesurada, aunque inexorable -ya que la mayor retención o prevención al delito vendría de la mano de ese castigo inevitable ${ }^{12}$ - y extenso en el tiempo -aunque menos intenso- (Beccaria, 1828, pp. 25-27, pp. 116-117 y pp. 179-180), alargando la duración de ese pequeño sufrimiento (Caro Pozo, 2013, p. 150).

Sin embargo, para llevar a cabo este nuevo modo de castigar, se requería de un lugar específico para su ejecución: la prisión.

Es entonces cuando abrió sus puertas en 1775 el Correccional de Gante, donde por vez primera la arquitectura se allana a las exigencias del castigo, pretendiendo facilitar las labores de vigilancia. Este edificio disponía de una planta octogonal con un patio central, dándose relevancia fundamental al tratamiento del recluso, con base al trabajo -evitando la molicie que inundaba el alma de los criminales ${ }^{13}$ (Ruiz-Morales, 2018b, p. 41).

12 Esto es, se iniciaría ineludiblemente un proceso penal, que sería inexpugnable. De nada valía castigar con la muerte o con suplicios, si el sujeto sabía que nunca iba a ser descubierto el delito, si se sabía impune.

13 La estancia no debía ser demasiado corta, ya que no cumpliría su finalidad de inculcar el espíritu trabajador; ni demasiado larga, puesto que sus pensamientos estarían centrados en planes de huida. 


\section{Las tesis en torno a la vigilancia y la disciplina: las sociedades de control}

En el cambio de centuria que se produjo entre los siglos XVIII y XIX, comienzan a cobrar protagonismo el sometimiento de cualquier faceta de la vida de los individuos a la disciplina y a la vigilancia ${ }^{14}$, aflorando en el mundo las -que se denominaron posteriormente- sociedades de control, bajo el auspicio del gobierno napoleónico que trasladó el modelo de esta sociedad disciplinaria a todos los ámbitos, desde la escuela, al hospital, o a la fábrica (Melossi y Pavarini, 2010, pp. 43-48) ${ }^{15}$.

No obstante, la sociedad de control por excelencia, no sería otra que la institución creada para ejecutar el encierro como castigo: la prisión.

Para Foucault, los cuatro pilares sobre los que se asentaban y asientan las sociedades de control son: la disciplina como distribución de los elementos con los que se cuenta, dividiéndolos de una determinada manera; el control o supervisión de la actividad, indicándose y fijándose cómo debe operar la correcta gestión del tiempo, esto es, los movimientos o el ritmo de las tareas; la enseñanza mutua, ya que los sometidos más experimentados controlan a los menos expertos, mientras que simultáneamente continúan con su proceso de aprendizaje; y la inmediata reacción a la orden, que debe ser sencilla, paladina, sin posibilidad de interpretación ni de menoscabar el ambiente de disciplina en el más absoluto silencio.

Por estos motivos, la arquitectura alcanzó un rol preeminente para las sociedades de control, en tanto en cuanto la disposición dada a las estructuras edilicias, podían facilitar las labores exigidas por estas sociedades disciplinarias. Ante tales prerrogativas, las construcciones de tal momento empezaron a perder el gusto por la ornamentación y el exterior del edificio, ya que la mirada se centró entonces en el interior, en lo que ocurría dentro, dominándose el cuerpo de los sujetos, sin ni siquiera atacarlo (Foucault, 1990, pp. 146-182).

\section{El prototipo arquitectónico de la doctrina disciplinaria: el panóptico}

En cierta manera, el nacimiento y el posterior establecimiento de las sociedades de control -propiamente dichas- fue consecuencia de la eclosión de las tesis utilitaristas durante el siglo XIX, principalmente de la mano de su teórico fundamental, Jeremy Bentham.

La prisión a principios del XIX fue vista por los reformadores como el lugar donde disciplinar a los desviados, a la vez que servía de amenaza a la sociedad (Rothman, 1998, pp. 111-112).

15 Es la época en la que la soberanía pasa al pueblo, en vez de quedar en manos del monarca; la disciplina le gana la partida al suplicio; la imposición del poder pretende construir en vez de reprimir (Foucault, 1990, pp. 33-34). 
Es interesante, en este sentido, observar cómo el pensamiento benthamiano trata gran parte de esta problemática en algunas de sus obras, a saber: en $\mathrm{El} \mathrm{Pa}$ nóptico o en su Teoría de las penas y de las Recompensas.

En esta última obra trataba las diversas modalidades de penas, y concretamente habló del encarcelamiento -incluso a veces desde un prisma puramente economicista- y del estado de las prisiones con que se encontró Howard. Dividió las cárceles en tres tipos, y abordó la explicación del panóptico, remitiendo al tercer volumen del Tratado de legislación civil y penal.

Aunque el propio filósofo londinense entendía que su prototipo podía utilizarse para cualquier edificio donde debiera primar la inspección, igualmente fue consciente de que su diseño gozaría de una gran utilidad en los establecimientos dedicados a la reclusión de personas y en los cuales se realizaban trabajos forzados. De esta manera, desarrolló su idea del proyecto "que todo lo ve" íntegramente, sin dejar de abordar ningún aspecto estructural ni de su posterior funcionamiento ${ }^{16}$ (Bentham, 1839, pp. 91-108).

El fundamento del arquetipo era el de "garantizar la existencia de un punto por todos observado, y desde el que cada uno piensa que puede ser controlado en cualquier momento" (Fraile, 1987, p. 132). Ahora bien, que el individuo estuviera cumpliendo una pena no era óbice para que el mismo se ejecutase de una manera lamentable, por ello las condiciones de luminosidad y de salubridad e higiene mejoraron considerablemente en el prototipo benthamiano -lo que mejoró la productividad en el trabajo-, mediante el uso de inmensos ventanales, ya que "quitar a un hombre su libertad no es condenarle a padecer frío ni a respirar un aire fétido" (Bentham, 1839, pp. 43-44).

Así, la disposición del edificio quedaba de la siguiente manera: "en la periferia, una construcción en forma de anillo; en el centro, una torre, ésta, con anchas ventanas que se abren en la cara interior del anillo" (Foucault, 1990, p. 203).

En la zona circular, se hallan las celdas, que se construirán ocupando toda la anchura del edificio, y que tanto por el lado que da al exterior, como por el que se ofrece a la torre central, estará provisto de amplias ventanales para que cada calabozo individual sea atravesado por la luz, y mediante las siluetas sombreadas que brinda ésta, se pueda conocer desde la torre central, la actitud que está teniendo el preso en todo momento. (Ruiz-Morales, 2018b, p. 43)

16 Atendió a la construcción, a sus ventajas, a la administración, a la separación y división, al trabajo, a la higiene, al alimento, al vestido, a la instrucción y el castigo, etc. en el Panóptico por él ideado. 
De esta manera, el panóptico -además- era economizador, al controlar constantemente al sujeto sin apenas supervisores, solo mediante la representación que se hacía el interno, en virtud de la cual se sentía constantemente observado -aun cuando no lo estuviera- (Foucault, 1990, pp. 205-208).

Sin embargo, a pesar de la influencia que significaron las tesis benthamianas, no se construyó ningún panóptico -desde su perspectiva teórica- en el mundo, toda vez que no se consiguió una total vigilancia del recluso, ni el total aislamiento del mismo, ya que podía oír lo que ocurría en el exterior de su celda. Además, para ganar en operatividad y rebajar los costes de este diseño, durante las primeras décadas del siglo XIX se prefirió edificar presidios de una mayor dimensión, asentados en el denominado "panóptico local", en el cabían más penados y se posibilitaba fácilmente la división entre ellos, mientras se vigilaba desde un punto de inspección central las diversas alas -bajo el amparo del sistema radial- (López, 1832, pp. 54-55).

Este modelo -radial- se utilizó desde 1829 en la Eastern Penitenciary de Filadelfia -en Estados Unidos- y se extendió por todo el orbe, siguiendo este modelo prisiones como la de Santiago (1843) -Chile-, Mendoza (1864) -Argentina-, la Penitenciaria Nacional (1874) -Argentina-, la Cárcel Modelo de Madrid (1884) -España-, la de La Paz (1896) -Bolivia-, el Presidio de Ushuaia -Argentina-y la Modelo de Barcelona (1904) -España- o la de Carabanchel (1944) -España-, manteniendo vigencia dicho arquetipo por más de un siglo ${ }^{17}$.

\section{Las novedades del cambio de siglo}

A lo largo del siglo XIX apareció un movimiento que atacó los postulados de la Escuela Clásica, ya que aquel movimiento entendió que la criminalidad debía estudiarse de una forma más científica -al estilo del resto de ciencias de la naturaleza- y no de una manera puramente dogmática, con la finalidad de prevenir la delincuencia y estudiar las causas que llevaban al individuo a delinquir. De este modo, surgió el positivismo criminológico.

Fue de esta manera como prosperaron las teorías sobre la prevención especial, basadas en la reeducación y readaptación del delincuente condenado, al efecto de no separar al individuo de la sociedad (Tinedo Fernández, 2008, p. 33). Por tanto, no es de extrañar que por ejemplo Ferri trabajase en tal línea, estableciendo medidas

17 Esta es la época de la reforma carcelaria, en la que se trataba el problema de las prisiones desde el punto de vista "médico" o "psicológico", apareciendo la noción del "incurable", el cual debía ser aislado totalmente de la sociedad. Esta corriente, entendía que el nivel de vida en los centros de reclusión debía ser muy inferior a la disfrutada por la población libre (Rusche y Kirchheimer, 1984, pp. 180-181). 
preventivas y de supresión de la peligrosidad del sujeto, con base en un tratamiento individual de acuerdo a las necesidades del penado (Elbert, 2001, p. 51).

Estos aspectos, además, fueron favorecidos por otras corrientes de las primeras décadas del siglo pasado, como la doctrina pedagógica penal, o el auge de disciplinas emergentes en las ciencias sociales, tales como la sociología o la antropología. De este modo, en virtud del primero de los avances, el tratamiento del penado alcanzó fines cuasi médicos, al configurarse como un verdadero régimen terapéutico (Ferrajoli, 1998, p. 265). Por su parte, las ciencias sociales contribuyeron al entendimiento del delincuente, como sujeto en el que el sistema social había errado en su proceso de socialización, por lo que la condena debía ir de la mano de una educación con la que imbuir valores sociales que permitieran la vida en comunidad (Zaffaroni, 1997, pp. 180-181).

Así, la aplicación penitenciaria de esta evolución doctrinal se produjo en el año 1898, de la mano del ingenio arquitectónico Henri Poussin, el cual proyectó la construcción de la Prisión departamental de Fresnes-les-Rungins, la cual marcó un hito en el ámbito de la arquitectura carcelaria, ya que con este presidio se inicia la senda de los complejos penitenciarios ${ }^{18}$.

Estos complejos han sido definidos como un "conjunto de establecimientos y servicios diferenciados, interrelacionado y coordinado para hacer efectiva una mejor individualización del tratamiento y una efectiva aplicación de las distintas fases de la progresividad del régimen penitenciario" (Paiva, 1966, p. 5), incluso posibilitando -en ocasiones- la autosuficiencia de la prisión o, al menos, el menor coste por recluso -respecto del mantenimiento- (Ruiz-Morales, 2018b, p. 47).

Además, estas modalidades penitenciarias rápidamente se extendieron y difundieron por todo el mundo, principalmente por la especial utilización de Alfred Hopkins. Sin embargo, los diseños utilizados fueron variados, desde la forma de espina, en "campus" -creando, dividiendo y subdividiendo a los reclusos en unidades funcionales y módulos con individuos homogéneos- (Margariños, 2008, p. 2) o incluso en altura, dependiendo de las necesidades del lugar.

Entre los complejos penitenciarios relevantes que se pueden mencionar, primeramente, se debe aludir al ideado por Hopkins para la Prisión de Lewisburg (1932). También la prisión de Rickers Island (1932), la Maison d’Arrêt de Fleury-Mérogis (1968), o más recientemente, los complejos penitenciarios tipo españoles -que son iguales entre ellos- y los complejos penitenciarios argentinos -que difieren entre ellos- (Bruno, 2006, pp. 8-13; García Basalo, 2003, pp. 63-75).

18 No obstante lo anterior, siguieron construyéndose prisiones bajo las premisas panoptistas de tiempos pretéritos, como ya se mencionó respecto de algunas prisiones del modelo radial que se edificaron durante el siglo XX. 


\section{El último medio siglo}

La relevancia dada a la resocialización, al tratamiento y la prevención fue considerable, por eso no debe extrañar que muchos de estos principios quedasen instituidos en las Reglas Mínimas para el tratamiento de los reclusos $(1957)^{19}$.

No obstante, con el paso de los años, la eficacia de la función resocializadora -y de las mencionadas reglas- fue quedando en entredicho, puesto que estas teorías y preceptos tenían un afán de universalidad, de difícil operatividad al tener que aplicarse en países muy diversos -algunos incluso antes de la ratificación ya habían cumplido con los compromisos adheridos, mientras que otros requerían de una modificación absoluta de su ordenamiento jurídico-penal, así como reconfigurar las penas y los castigos- (Mapelli Caffarena 2006, pp. 1-4). Igualmente, existieron otros aspectos problemáticos que condenaron a la resocialización, tales como el uso masivo de la pena de prisión -lo que causó una enorme sobrepoblación carcelaria, contraria a los fines resocializadores- o la nocividad propia de la reclusión en la institución penitenciaria -que atenta contra la sociabilidad del individuo-. Todo ello fue provocando el paulatino abandono de las prácticas resocializadoras (Téllez Aguilera, 1996, pp. 100-107).

Ante tal situación, las últimas décadas se caracterizaron por dos tendencias diversas de signo contrario: una, la vuelta a las tesis de la resocialización -eliminando los elementos negativos que coadyuvaron a su derrocamiento-; dos, la recuperación de los postulados más restrictivos, propios de las sociedades de control ${ }^{20}$.

\subsection{La vuelta a la reinserción}

Las corrientes garantistas han venido promoviendo desde hace años un nuevo giro en torno al amparo de la dignidad y la humanidad del interno en un establecimiento penitenciario. Es por ello que Baratta (1999) se decantaba por

La premisa según la cual la reintegración social del condenado no puede y no debe hacerse a través de la pena (detentiva), sino, contra la pena, vale decir, contrarrestando los efectos negativos que la privación de libertad ejerce sobre sus oportunidades de reinserción. (p. 72)

19 Se adoptaron en el Primer Congreso de las Naciones Unidas sobre Prevención del Delito y Tratamiento del Delincuente (1955), pero se aprobaron dos años más tarde, y también en 1977.

20 Algún autor se refirió a esta circunstancia como consecuencia de la política penitenciaria, toda vez que la misma no es única -sino que es plural- dependiendo del parecer que el aparato gubernamental estatal estime más idóneo para ejecutar el castigo. De este modo, habría políticas penitenciarias centradas en la resocialización -vía prevención especial positiva-, y habría otras de corte más securitario -amparadas en la emergencia penal- (Cesano 2017, p. 12). 
Por tanto, esta "nueva" socialización pretendía eliminar o, al menos, paliar aquellos ámbitos del condenado que sufren un menoscabo durante la ejecución de la condena que lo privaba de libertad -caso de fracturas de relaciones familiares, relaciones entre reclusos o shock posreclusión- (Tinedo Fernández, 2008, pp. 39-42).

En definitiva, es aquello que Zaffaroni denominó "el trato humano reductor de la vulnerabilidad", en virtud del cual:

Un programa concebido sobre esta base tendría un objetivo claro y posible: agotar los esfuerzos para que la cárcel sea lo menos deteriorante posible, tanto para los prisonizados como para el personal; permitir que en cooperación con iniciativas comunitarias se eleve el nivel de invulnerabilidad de la persona frente al poder del sistema penal. (Zaffaroni, 1997, p. 186)

Estas previsiones teóricas recibieron la acogida de normalización necesaria para asegurar su cumplimiento -a nivel global- por medio -primeramente y sectorialmente- de las Reglas o Normas Penitenciarias Europeas, adoptadas el 11 de enero de 2006 por el Comité de Ministros del Consejo de Europa y -posteriormente- por la revisión de Las Reglas Mínimas de las Naciones Unidas de 1957, que culminaron con la proclamación de Las Reglas Mínimas de las Naciones Unidas para el Tratamiento de los Reclusos (Reglas Mandela), del 4 de mayo de 2015 ${ }^{21}$.

De esta manera, las peculiaridades manifestadas requerían de ciertas innovaciones en el ámbito arquitectónico, que quedaría expuesto en el propio diseño de la cárcel, la cual se debía asemejar al estilo de cualquier edificio público, para eliminar así la presión ambiental y visual -toda vez que el propio edificio proyecta una imagen y un significado- (Ruiz-Morales, 2018b, p. 51).

Como ejemplos de estas prisiones vanguardistas en el campo de la reinserción social y la no reincidencia del ex-recluso, se pueden mencionar algunas prisiones de países nórdicos y del norte y centro de Europa.

Entre ellas se debe aludir al austriaco Justice Center Leoben (2004) -en el que prima la entrada de luminosidad en el interior, el uso del cristal, la ventilación, las vistas del exterior y una serie de espacios múltiples para los momentos de ocio, puesto que los reclusos trabajan mientras están internados (Lewis, 2009)-; la Cárcel de Handel Fengsel (2010) -considerada una de las prisiones más humanas del mundo, facilitando la adaptación y favoreciendo la habitabilidad y la sociabilidad del sujeto mediante la integración de un numeroso y altamente capacitado equipo humano en el trato con la población reclusa, además de utilizar el diseño,

21 Recuérdese también las Reglas de Bangkok del 16 de marzo de 2011, que surgieron tras constatar que los reclusos tienen diversas necesidades dependiendo de su sexo, por la que se disponen medidas para el tratamiento de las reclusas. 
la decoración e, incluso, la vegetación, como piezas esenciales para disminuir la presión ambiental (Benezic, 2016)-; la Prisión de Storstrøm (2017) -que cuenta con una verdadera trama urbana, con diversos espacios y calles, como una ciudad en miniatura ${ }^{22}$ (Zuleta, 2011)-y la Prisión de la isla de Bastoy (1982) -que a pesar de ser la más antigua de las enumeradas, fue muy revolucionaria en su momento, al permitir la vida en libertad de los internos dentro de sus límites costeros -en sus propios bungalows ${ }^{-23}$, manteniéndose la misma de forma autosuficiente mediante el trabajo de los reclusos (James, 2013)-.

\subsection{El retorno de las sociedades de control}

En las últimas décadas, igualmente, se ha producido una evolución tecnológica exponencial, que ha afectado a casi todos los ámbitos de la ciencia. Estas nuevas tecnologías gozan de un potencial enorme para desarrollar sistemas de control en cualquier faceta de los individuos y, como es lógico, mucho más en el lugar en el que se cumple una pena privativa de libertad.

En estos modelos penitenciarios y carcelarios, en los que prima el control, los derechos y libertades del recluso ${ }^{24}$-como su intimidad- (Estrada Cuzcano, 2005, pp. 150-161) o su menesterosa rehabilitación social quedan relegados a un segundo plano -cuando no son desdeñados absolutamente-.

Por ende, el control del sujeto en la actualidad, puede ser total, quedando inspeccionado y grabado cualquier movimiento del condenado, a través de los diversos medios telemáticos disponibles y sin apenas necesidad de recursos humanos que controlen in situ la prisión -con el paladino y correlativo ahorro en costes laborales-.

Pero a mayor abundamiento, hace unas cuatro décadas apareció un novedoso diseño -denominado diseño podular- especial para organizar las unidades funcionales de cualquier centro penitenciario (García Basalo, 2018, pp. 7-8). No obstante, este arquetipo tenía poco o nada de novedoso, toda vez que presenta ciertas similitudes con las tesis benthamianas en torno al panóptico.

Así, este arquetipo podular consiste en constituir unidades funcionales o módulos de unos treinta o cuarenta reclusos, con una forma triangular, de manera que las celdas o habitaciones quedaban alrededor de un puesto de control

22 Es considerada la prisión más humana en la actualidad. Con celdas individuales, que garantizan la privacidad. Cuenta con múltiples espacios y se configura como una pequeña ciudad, con su centro y sus zonas residenciales en las que prima el vanguardismo.

23 Se considera que la sanción consiste meramente en rehabilitación y no en castigo, aseveración confirmada en virtud las nimias cifras de reincidencia que posee.

24 No se debe olvidar que antes que recluso es persona, poseedora de unos derechos humanos inalienables. 
-que permitiría supervisar con una simple mirada las diversas celdillas-. Ahora bien, si dicho puesto de control se halla en el exterior de la unidad, se habla de observación remota -control puro- ${ }^{25}$; mientras que si el supervisor vigila desde el propio interior de la unidad, se habla de supervisión directa -ya que, al integrarse el vigía con la población reclusa, este hecho favorecería, a priori, la rehabilitación-.

Por su parte, como prisiones en las que prevalece el control se pueden mencionar el Centro Souza Baranowski (1998) -prisión tecnológica que dispone de uno de los sistemas de vigilancia más potentes del mundo, de ahí que cuente con más de cuatrocientas cámaras, sensores de movimientos, etc., lo que la hacen inexpugnable-, la Penitenciaría de Terre Haute (2004) -que cuenta con un sistema de seguridad único, puesto que además de lo anterior, utilizan incluso el reconocimiento facial y el candado biométrico, con unos módulos triangulares ${ }^{26}{ }_{-}$, o las prisiones antiguas que son equipadas con sistemas de vigilancia actuales para convertirlas en un lugar inquebrantable, un espacio de control absoluto, sin necesidad de contar con gran cantidad recursos humanos -como es el caso de La Santé- (Ruiz-Morales, 2018b, pp. 53-54).

De esta manera, se puede concluir que estas cárceles están ideadas prevaleciendo más las ideas en torno al control, en evitar la evasión -de cualquier manera-, más que en el individuo y sus necesidades, de ahí que los recursos financieros disponibles para su diseño y equipamiento se dirijan a cumplir con tales menesteres.

\section{La verdadera realidad: la inocuización}

A pesar de que evidentemente existen dos caminos diferentes a la hora de entender hoy en día el castigo referente a la pena privativa de libertad -la cual sigue siendo la primordial en el sistema de penas de los ordenamientos jurídico-penales del mundo-, habiéndose construido -por un lado- prisiones desde una perspectiva más garantista, más humana, en virtud de la denominada arquitectura penitenciaria de cuarta generación ${ }^{27}$, y -por otro lado- habiéndose edificado -por gran parte

25 El diseño podular tiene un fundamento panóptico, sin demasiada innovación, puesto que, en vez de referirse a la totalidad de la prisión, se trata de solo un módulo o una unidad funcional. No obstante, presenta bases benthamianas, al tratarse de un punto desde el que se controla todo -esta vez, bajo la forma triangular-. Por tanto, el diseño podular parecería haberse utilizado -sin conocer tal estructura arquitectónica- en el Correccional de Gante -cuando aún no había surgido el panóptico como tal-, máxime si se tiene en cuenta que dicha prisión se dividía en unidades separadas triangulares a partir de un patio central.

26 Lo que serviría para implantar el diseño podular. En este sentido, es mencionable el Complejo Penitenciario de Ezeiza donde las unidades funcionales utilizan el diseño podular de una manera absoluta -remotamente-, toda vez que los diversos módulos se organizan a su vez triangularmente, para supervisar podularmente incluso en el exterior de las unidades.

27 La cuarta generación surgió tras la posguerra y se fundamenta en la instauración de grupos pequeños de reclusos, debiendo existir una correlación total entre la arquitectura y las necesidades tratamentales. Algunos de sus principios elementales serían: cercanía e integridad de la prisión en la comunidad, la prisión semiabierta de seguridad 
del mundo- complejos penitenciarios en los que se antepone un incondicional y omnímodo control del recluso ${ }^{28}$; lo cierto es que el sistema penal desde mediados del siglo XX tiende meramente hacia la inocuización del individuo, incluso en aspectos extrapenales de las personas.

De este modo, si se atiende a la definición que de inocuo ofrece la Real Academia Española, se refiere a aquel o aquello "que no hace daño". Por tanto, la inocuización consistiría en convertir a un sujeto en inofensivo, en neutralizar el eventual peligro que el sujeto puede suponer, incapacitándolo criminalmente (Magallanes Maldonado, 2002).

Pues bien, este es el objetivo que se instaura en todo el orden penal actual, que pretende neutralizar la potencial amenaza de que se produzca un hecho dañoso para la sociedad, mediante el resurgimiento del control, un control extremo de los individuos -que coarta las libertades fundamentales, so falaces excusas de seguridad-.

\subsection{La inocuización en prisión: la cárcel "depósito"}

Aun cuando -como ya se mencionó ad supra- las Reglas Mínimas para el tratamiento de los reclusos -en sus distintas ediciones- aludían a la necesidad de resocializar al individuo como una finalidad de la pena, estas mismas reglas contenían indicaciones tendentes a la neutralización del delincuente, que han servido de justificación para separar a este de la sociedad.

Así, conforme a la Regla 58 de las Reglas Mínimas para el tratamiento de los reclusos de 1957:

El fin y la justificación de las penas y medidas privativas de libertad son, en definitiva, proteger a la sociedad contra el crimen. Sólo se alcanzará este fin si se aprovecha el período de privación de libertad para lograr, en lo posible, que el delincuente una vez liberado no solamente quiera respetar la ley y proveer a sus necesidades, sino también que sea capaz de hacerlo. (Regla 58)

dinámica, debe internar a un número limitado de reclusos -no más de trescientos-, debe configurarse como una ciudad -trama urbana- con los distintos barrios, la seguridad se obtiene con el diseño -sin utilizar extensivamente barreras físicas-, debe poseer ambiente residencial que favorezca la interacción social entre sus habitantes, así como que permita la normalización de la vida -de acuerdo a una buena psicología ambiental-, en ellas se fijan de espacios personales -a través de dormitorios individuales-, entre otros fundamentos. Por su parte, la primera generación sería la arquitectura lineal que se producía cuando la vigilancia era intermitente, al recorrer un guardia el pasillo de una prisión. La segunda, vendría dada por el diseño podular en vigilancia remota. Y la tercera generación se configuró conforme al diseño podular en supervisión directa (García Basalo, 2018, pp. 7-13).

28 Piénsese simplemente en el funcionamiento del centro penitenciario tipo español, o en la reciente construcción del Complejo Penitenciario Federal III, del Noroeste argentino, que para nada cumple con las exigencias de la cuarta generación, situándose entre la segunda y la tercera generación. 
En un sentido similar, se pronunció la Regla 4. 1 de las Reglas Mínimas de las Naciones Unidas para el Tratamiento de los Reclusos (Reglas Nelson Mandela) de 2015, al indicar que "los objetivos de las penas y medidas privativas de libertad son principalmente proteger a la sociedad contra el delito y reducir la reincidencia".

Por tanto, a pesar de que dichas reglas hacen referencia al menesteroso tratamiento penitenciario, se fija -igualmente- la finalidad que debe cumplir la pena privativa de libertad -que no es otro que el proteger a la sociedad-, ofreciendo como una especie de plácet a la inocuización de los penados bajo la falsa apariencia de la resocialización ${ }^{29}$.

Sin embargo, la tendencia que se está enunciando en estas líneas no es para nada algo novedoso, puesto que ya a mediados del siglo pasado aparecieron voces que afirmaban que la prisión contenía -y contiene- al recluso, es decir, guardaba -y guarda- al delincuente de la sociedad, sin corregirlo (Ruiz Funes, 1949, pp. 7-8). Esta aseveración ha sido confirmada incluso en cierta obra dedicada al estudio de la arquitectura penitenciaria de las cárceles argentinas de mediados del siglo XIX y principios del XX, ya que uno de los mayores especialistas del mundo en esta materia proclamaba en el propio título de una de sus investigaciones que la prisión es una institución "para seguridad y no para castigo"30.

Estas argumentaciones muestran cierta relación con las exposiciones y teorías de la prevención especial positiva, donde el tratamiento penitenciario y la resocialización adquieren un papel fundamental, de una similar manera a lo dispuesto en las recurrentes Reglas Mínimas. No obstante, ni siquiera esta vertiente de la prevención especial es generalmente cierta, ya que

Sabemos que la ejecución penal no resocializa ni cumple ninguna de las funciones "re" que se la han inventado -"re" socialización, personalización, individuación, educación, inserción, etc. -, que todo eso es mentira y que pretender enseñarle a un hombre a vivir en sociedad mediante el encierro es [...] absurdo. (Zaffaroni, 1993, p. 43)

Pero es que además, por su parte, la vertiente negativa de la prevención especial supera esta crítica a la ejecución penal en prisión y ampara ese aislamiento, esa neutralización, esa eliminación o inocuización del sujeto delincuente, excluyéndolo del sistema social (Pérez Tolentino, 2012, pp. 3-5).

29 En este sentido, es curioso observar cómo ambas reglas mencionan antes la necesidad de proteger a la sociedad que la función resocializadora, por lo que parece dejar entrever que primero se cumple con el aseguramiento de la sociedad -lo que se produce con la separación o alejamiento del sujeto peligroso de la comunidad-y ya después se utilizarán programas para reducir la reincidencia -en la medida de las posibilidades-.

30 Se está haciendo alusión a la obra del profesor García Basalo: Para seguridad y no para castigo. Origen y evolución de la arquitectura penitenciaria provincial argentina (1853-1922), publicada en 2017. 
Esta prevención especial negativa no es una solución novedosa y actual, puesto que a principios del siglo XX von Liszt explicó que cuando el individuo había demostrado ser un incorregible y -por tanto- no podía ser reinsertado, se legitimaba la inclusión de la inocuización como una finalidad de la pena en el ámbito de la prevención especial, al no ser funcional la intimidación individual -delincuente ocasional-, ni la resocialización -delincuente ocasional corregible- (von Liszt, 1905, pp. 126-129 y pp. 164-169), puesto que contra los incorregibles debe la sociedad protegerse [...] y como no queremos decapitar ni ahorcar, y no podemos deportar, sólo queda la cadena perpetua -o por tiempo determinado-.

Por tanto, este jurista vienés justificó la neutralización del delincuente -incorregible- mediante la cadena perpetua o al menos por el tiempo determinado más extenso posible.

Sin embargo, si los programas de tratamiento -prevención especial positivason ineficaces y absurdos -como ya se comentó-, siendo además, que en la prisión prima la protección de la sociedad antes que cualquier otra finalidad, ¿no se usa actualmente entonces tal institución simplemente para inocuizar a individuos?

Parece que no queda otra opción que afirmar esta proposición, ya que de otra forma resultaría imposible justificar la existencia en los ordenamientos jurídicos de instituciones vigentes al estilo de la custodia de seguridad alemana -Sicherungsverwahrung- (Silva Sánchez, 2001, p. 699-700), o de instituciones cercanas a la cadena perpetua.

Además, como ya algún autor llamó la atención sobre el particular, se debe recordar que el control del delito ha ido en aumento desde la década del setenta, ampliándose las funciones y el número de recursos disponibles -de distinta índole- en el ámbito policial; desmesurándose el derecho penal -ultrarregulando aspectos sociales que escapan tradicionalmente del poder punitivo estatal y a los que debería responderse desde otras ramas del ordenamiento para no menoscabar el principio de intervención mínima o la categoría del derecho penal subsidiario o fragmentario, esto es, su operatividad como ultima ratio-; y haciendo surgir un nuevo sector de control delincuencial -desde el propio aparato gubernamental-con organizaciones que previenen el delito, con empresas de seguridad que proliferan sin cesar, con protección de lugares privados y públicos, que se sitúa en un espacio propio de la sociedad civil, extendiendo el mencionado control formal más allá del poder estatal (Garland, 2005, pp. 279-282).

En el ordenamiento jurídico-penal español resultan fácilmente identificables estas medidas tendentes a la senda inocuizadora del delincuente, toda vez que se puede mencionar la tipificación -en los últimos años- de la pena de prisión permanente revisable, o la fijación de la medida de libertad vigilada, establecidas en nuestro Código Penal, que tienden a la neutralización de la peligrosidad del sujeto, bien manteniendo al individuo delincuente en prisión por un tiempo que tiende 
hacia el infinito -como una pseudocadena perpetua- ${ }^{31}$, bien aplicando el control más absoluto y férreo tras haber cumplido el individuo su condena y haber vuelto el sujeto a la sociedad.

No obstante, cada cierto tiempo aparecen nuevas noticias e informaciones en las que algún partido político se plantea ampliar el catálogo de delitos a los que imponer esta cadena perpetua simulada -máxime tras la radicalización de la derecha política española con la irrupción del partido de nueva creación VOX-. En este sentido, recientemente aparecía en los medios de comunicación la intención del Partido Popular de castigar la rebelión y otros seis hechos típicos con esta modalidad de pena (Lamet, 2019). A mayor abundamiento, el crimen de Lara Luelmo volvió a poner en la palestra el debate político sobre esta pena contenida en el ordenamiento español, entre los que desean mantenerla y ampliar los supuestos en los que podría entrar y los que se decantan por su derogación.

Igualmente, la tendencia hacia la inocuización del delincuente se pudo observar -también- en el proyecto de reforma del Código Penal español que se cristalizó en 2015, puesto que en las redacciones anteriores -cuando la propuesta de modificación era meramente un anteproyecto-, se contenía -además de la prisión permanente revisable- la custodia de seguridad, a pesar de la manifiesta inconstitucionalidad de tal medida, incluso en el ordenamiento alemán -donde se encontraba su origen-.

Por último, se debe mencionar la larga duración de las penas privativas de libertad en el Código Penal español. En este sentido, -sin afán de exhaustividad-se puede advertir, por ejemplo, cómo para los delitos de tráfico de drogas, la regulación anterior a la reforma de 2010 -por Ley Orgánica 5/2010, de 22 de junio- contenía simplemente normas penales opresivas ${ }^{32}$, que perseguían meramente la represión de los delincuentes y su mantenimiento en prisión ${ }^{33}$ (Botella Soria, 2010, p. 3).

Sin embargo, esta senda inocuizadora no es propia únicamente de nuestro país, sino que más bien se trata de un fenómeno global. Para sostener tal premisa, bastaría simplemente con recordar algunos ejemplos de tendencia hacia la neutralización en otros países ${ }^{34}$.

31 Este era uno de los fundamentos usados también para aplicar la "Doctrina Parot".

32 Se castigaba el narcotráfico con penas excesivamente altas y cercanas a las del homicidio y/o al asesinato, a las que podía superar en casos de acontecer alguna agravante al supuesto concreto.

33 En tal sentido, es destacable que las normas europeas en la materia exigían la fijación de una sanción penal para tal tipología delictiva. No obstante, la severidad de las normas penales españolas superaba con creces a los requerimientos impuestos en la Decisión marco 2004/757/JAI del Consejo, de 25 de octubre de 2004, lo que obligó a reconfigurar el sistema penal español en la materia, acotando el rigor punitivo español en el tipo básico de narcotráfico.

34 En este sentido, se puede señalar cómo se está produciendo un fenómeno de auge de las "derechas" en el mundo actual. Basta mencionar los mandatos conservadores de Donald Trump, Vladimir Putin, Angela Merkel, Emmanuel Macron, Theresa May, Mauricio Macri o Jair Bolsonaro, entre otros. 
En primer lugar, en este apartado, se debe mencionar el ejemplo de la Argentina y la promulgación de las denominadas Leyes Blumberg -Ley 25.886, entre otras- en 2004, que conllevó la aprobación de medidas como que: la pena máxima se aumentase hasta llegar a los cincuenta y cinco años de prisión, el cumplimiento efectivo de treinta y cinco años de prisión para acceder a la libertad condicional, o que ciertos delitos -como el robo con arma de fuego, la tenencia y portación de tales armas, o el homicidio subsiguiente a un delito contra la integridad sexual, entre otros- vieran aumentadas sus penas de prisión, etc.

En segundo lugar, es destacable que un país "democrático" como Estados Unidos, permita que sus Estados apliquen todavía hoy la pena capital, manteniéndose vigente -y por tanto, considerándose legal- esta tipología de sanción penal en más de una treintena de Estados federados, aun cuando no se aplique la misma en la mayoría. De este modo, mediante la utilización de este castigo, se produce la total inocuización del delincuente, toda vez que el "peligro que supone para la sociedad", es eliminado ${ }^{35}$.

En tercer término, resulta curioso que un Tribunal -como es el Tribunal Europeo de Derechos Humanos- que debe de velar por el cumplimiento de los derechos humanos, garantizando la protección de los mismos con base en tales derechos y libertades reconocidos en el Convenio para la Protección de los Derechos Humanos y de las Libertades Fundamentales (CEDH) o en cualquiera de sus protocolos, a la hora de pronunciarse sobre medidas tendentes a la inocuización de los delincuentes -tales como la pena de prisión permanente revisable-, se haya situado del lado de dicha neutralización, avalando tal modalidad de sanción penal, siempre y cuando existiera la posibilidad de revisar la condena -aun cuando fuere extremadamente larga o indeterminada ${ }^{36}$.

En cuarto lugar, este es el fundamento -parcial- de recluir en prisión al presunto sospechoso de haber cometido una actividad delictuosa. Se está haciendo alusión, a la siempre discutida prisión preventiva ${ }^{37}$, consistente en neutralizar al supuesto autor de un crimen, aun cuando no se haya determinado su responsabilidad en el mismo.

Ante este panorama no es de extrañar que en más de una ocasión se haya atribuido el adjetivo "depósito humano" a la prisión, toda vez que ha funcionado únicamente como un lugar para contener a sujetos en su interior y evitar su esparcimiento y derramamiento de estos por la sociedad.

35 En la actualidad -dato de 2018-, cerca de tres mil reclusos -2.743- siguen esperando en el corredor de la muerte. Fuente: NAACP Legal Defense and Educational Fund.

36 STEDH Kafkaris c. Chipre, de 12 de febrero de 2008; STEDH Meixner c. Alemania, de 3 de noviembre de 2009; STEDH Affaire Bodein c. Francia, de 13 de noviembre de 2014; y STEDH Hutchinson c. Reino Unido, de 3 de febrero de 2015.

37 Por su propia naturaleza esta figura debe ser considerada cuasi ilegal al adelantarse una condena a un individuo ante unas meras "sospechas de criminalidad" (Vitale, 2007, pp. 15-23). 
La prisión-jaula o prisión-depósito, por su parte, se caracteriza por los altos volúmenes de encarcelamiento ${ }^{38}$, por la alta cantidad de presos preventivos habitando las cárceles, por la superpoblación y el hacinamiento, así como las condiciones de vida y la violencia que se ejerce en el establecimiento penitenciario, que se produce -en mayor medida- en los centros donde se ejerce más específicamente el control ${ }^{39}$.

Estas cárceles se caracterizan por diseños para albergar a infinidad de personas -lo que reduce las posibilidades de tratamiento, al disminuir la calidad del mismo-, aunque se dispongan como instituciones autónomas dentro de un "complejo penitenciario", toda vez que carecen de urbanismo y de espacios abiertos, separando al interno del personal de la prisión. Igualmente, presentan dormitorios o alojamientos colectivos ${ }^{40}$, a la vez que se construyen en las afueras de las ciudades o en lugares alejados a las mismas ${ }^{41}$. Además, estos establecimientos penitenciarios se edifican ideados -mayoritariamente- para albergar a sujetos de una misma manera -máxima seguridad-, aun cuando existan muy pocos presos de esta tipología y, por tanto, el resto no requiera de tal fisionomía carcelaria ${ }^{42}$ (García Basalo, 2018, pp. 4-7).

Ahora bien, también existen cárceles más humanas -como ya se estudió en el epígrafe 7.1., cuando se trataron las prisiones más vanguardistas y más preocupadas por la resocialización-, situadas en el territorio noruego, danés y austriaco. Sin embargo, no se debería olvidar que aún humanas, se trata de prisiones ${ }^{43}$, que alejan al individuo de la sociedad en la que vive, al efecto de inocuizarlo. Igualmente, en prisiones humanas como la de la isla de Bastoy, por un lado, parece ser que se aplica una especie de neutralización o "inocuización descontrolada", toda vez que en ellas cede un poco la idea de control interno, de dicotomía vigilante-recluso, aunque, por otro lado, se separa el peligro que supone el delincuente para la sociedad y

Es lo que se ha denominado "extensión horizontal de la red penal" (Wacquant, 2004, pp. 91-93).

39 El populismo punitivo también contribuye a la superpoblación de la prisión, convirtiéndola en un depósito (Sozzo, 2009, p. 50). En este sentido, -v. gr. - baste recordar -para el caso español- las altas penas para el tráfico de drogas, mencionadas ad supra, que contribuían a aglomerar los establecimientos penitenciarios españoles. Este populismo punitivo puede observarse -igualmente-, en las últimas reformas del Código Penal, específicamente en 2015, con la inclusión de la prisión permanente revisable, como resultado de las pretensiones de castigo de familiares de víctimas y el apoyo social recibido. V. gr. piénsese en casos como el de Mari Luz Cortés, el de Marta del Castillo o José Breton, que sacudieron a la sociedad española del momento -al estilo de los posteriores de La Manada, Diana Quer, o más recientemente, el caso de Gabriel Cruz o hace unos días, el caso valenciano de María Gombau-.

40 Para el efectivo cumplimiento de los requerimientos de las Reglas Mandela, se necesita un espacio de unos cuarenta metros cuadrados por recluso.

41 Alejando simbólicamente al delincuente de la sociedad.

42 Ante tales requisitos, no se puede sino afirmar que los centros penitenciarios tipo españoles son un prototipo de prisión-depósito, máxime si se tiene en cuenta el imparable crecimiento de la población reclusa española desde la instauración de la democracia y hasta 2009. Así, aunque en los últimos años la población penitenciaria española está retrocediendo, ello no es óbice para considerar que las prisiones españolas actúan como jaulas humanas en las que los individuos habitan hacinados (Daunis Rodríguez, 2016, pp. 476-479). 
se lo aleja de la misma, recluyéndolo en una isla, donde no tiene posibilidades materiales de entrar en contacto, ni de dañar mínimamente a la sociedad ${ }^{44}$.

\subsection{La inocuización de la sociedad}

A pesar de la neutralización de los individuos peligrosos para la sociedad internándolos y alejándolos de la misma, en la propia sociedad actual existen y existirán potenciales amenazas de lesión o menoscabo de los bienes jurídicos más importantes para el desarrollo de la vida humana.

Es por ello que hogaño el control de las acciones de los miembros que conforman nuestra sociedad es infinito, en virtud de los medios tecnológicos de los que hoy en día se disponen.

Por tanto, los gobiernos del mundo utilizan todos los métodos posibles para adelantarse a posibles ataques que pongan en riesgo su preeminente poder. Así, bajo la argucia del mantenimiento del orden público o por razones puramente securitarias, se normalizan ${ }^{45}$-conforme a las leyes vigentes, las cuales son reformadas- situaciones de constricción casi absoluta de la libertad que deben poseer los ciudadanos, organizándose entonces como una especie de "neutralización ex ante", esto es, una eliminación de cualquier potencial riesgo de desorden o inseguridad pública, aun cuando este ni siquiera es previsible que suceda.

Este fenómeno puede observarse claramente en el siguiente ejemplo, puesto que dicha restricción y neutralización es mayor para determinados grupos: parece que existe como una especie de miedo al extranjero o el inmigrante -xenofobia-, ya que este -por su propia condición foránea- supone una amenaza para el oriundo. No obstante, aun cuando este individuo extranjero no represente ningún riesgo, ese sector poblacional será especialmente vigilado, controlado, inocuizado, como parte de una política criminal estigmatizadora de ese grupo social, lo que termina por situarlo en una situación de marginación social ${ }^{46}$.

44 Por tanto, se estaría ante un panorama de "descontrol extra-controlado": descontrol en el sentido de no control, ya que el interno vive en total libertad dentro de la prisión; extra-controlado, puesto que no existe mayor nivel de control, de neutralización de una amenaza, que situarla a kilómetros de la sociedad, aunado a una barrera marítima.

Téngase en cuenta que el castigo ha venido a conformar parte de nuestra cultura, siendo usada para controlar desde el poder a la sociedad, mediante la autoridad, la moralidad, las relaciones sociales correctas o permitidas, los signos y símbolos, entre otros (Garland, 1999, pp .290-300).

46 Se está haciendo referencia al proceso de selección en la persecución penal, conforme a la Teoría del Labeling Approach y sus grados de selección -fijación de figuras delictivas, la denuncia del perjudicado, las averiguaciones y las actuaciones de los órganos de persecución penal, las posibilidades de sobreseimiento, las decisiones judiciales y la opinión pública- (Zipf, 1979, pp. 116-119) y a la criminalización secundaria de este colectivo marginado. En este sentido, parece bastante evidente este fenómeno si se observan someramente las estadísticas del Instituto Nacional de Estadística (INE). Según los datos para finales de 2017, el 9,8 \% de la población residente en España era población extranjera; sin embargo, la población reclusa extranjera en las cárceles españolas -en ese mismo momento- superaba el 28 \% de la población penitenciaria española total. A lo que se podría añadir que la mayoría de los reclusos 
Y es que las formas de castigar a los individuos sobre los que recae la reclusión y las razones de sancionar con la privación de libertad en prisión, sirven como herramienta para controlar el delito y para que el resto de ciudadanos -a través de los medios de comunicación ${ }^{47}$ - se representen los comportamientos que el Estado no permite, esto es, para que la comunidad conozca paladinamente aquellos ámbitos que los individuos no podrán transgredir y/o sobrepasar, con la finalidad de a través del control del delito, controlar también a la sociedad ${ }^{48}$ (Melossi, 2018).

Sin embargo, este control de la sociedad está yendo más allá, en tanto en cuanto los ordenamientos jurídicos del mundo están conteniendo leyes que restringen libertades elementales y básicas. De este modo, se pretenden neutralizar eventuales situaciones de descontrol o desorden público, a costa de restringir derechos inalienables de las personas como el derecho a la manifestación, la reunión o la libertad de expresión. Es el caso de la española la Ley Orgánica 4/2015, de 30 de marzo, de protección de la seguridad ciudadana. Esta ley surgió ante "supuestos" "problemas de multirreincidencia y de violencia callejera" ${ }^{49}$.

No obstante, la reforma más gravosa respecto a lo que a la inocuización de la propia sociedad se refiere, se produjo también en el particular español en el año 2015, toda vez que la Ley Orgánica 13/2015, de 5 de octubre, de modificación de la Ley de Enjuiciamiento Criminal para el fortalecimiento de las garantías procesales y la regulación de las medidas de investigación tecnológica, introdujo la posibilidad de que -con los medios tecnológicos disponibles hoy en día- la Policía Judicial grabase -esto es, vigilase- la actividad de cualquier individuo, sin requerir de autorización judicial, cuando el mismo se hallare en un espacio público "si ello fuera necesario para facilitar su identificación, para localizar los instrumentos o efectos del delito u obtener datos relevantes para el esclarecimiento de los hechos ${ }^{50 ”}$.

Por tanto, las opciones que ofrece la redacción literal del precepto son muy amplias, ya que "para identificarlo" o para "obtener datos" que diluciden el hecho

extranjeros en España, pertenecen a unas pocas nacionalidades, que son fácilmente identificables por sus rasgos físicos. Ante tal hecho, ¿por qué no se criminaliza igualmente a los inmigrantes del norte de Europa que se asientan y residen en lugares de la costa española? Aún a sabiendas de alejarnos del propósito final de este trabajo, se debe mencionar que en definitiva se trata de un problema de desigualdad económica, de inequidad, de pobreza y cómo el sistema penal trata a esos colectivos sociales vulnerables y marginales, en la línea de los trabajos de autores como Melossi (1980, 2015) o Ruiz Rodríguez (2006) -para el caso español-.

47 A través de los medios se crean y se introducen temas penales en la opinión pública, que serán los aspectos que preocuparán -luego- a la ciudadanía -de acuerdo a la teoría de la agenda setting-, que impulsa la incorporación -incluso- de tipos penales (Ruiz-Morales, 2018c, pp. 625-630).

48 Mediante los distintos modelos que pueden considerarse de control social y su expansión de los modelos estadounidenses a Europa (Melossi, 2018).

49 En otros países del mundo han surgido también legislaciones de corte similar, denominadas también -como ocurre en España con la citada LO 4/2015- con el apelativo de "leyes mordaza".

50 Art. 588 quinquies a) 1 . 
investigado, el individuo puede ser vigilado a cualquier hora, de cualquier día, nada más salga de su domicilio, a la espera de la prueba irrefutable de delito.

Así es que, si todos fuéramos controlados en todo momento, sin requerir de garantía judicial alguna en los espacios públicos -donde tradicionalmente se cometen los delitos-, tarde o temprano cometeríamos alguna infracción penal, y es que en realidad estaríamos -en realidad, ya estamos ${ }^{51}$ - sometidos a una medida de seguridad pre-delictual constante e indefinida en el tiempo.

Es decir, sobre todos recae una suerte de peligrosidad o una especie de sospecha de criminalidad, que habilita al poder estatal a vigilarnos las veinticuatro horas, como si se tratase del Gran Hermano de Orwell, en esa ficción distópica de represión policial y opresión, descrita por este autor en su obra $1984^{52}$.

Esta situación se está viendo intensificada tras la crisis generada por la pandemia del coronavirus a nivel global, toda vez que el control de los contagios, así como de los contactos de las personas infectadas por el COVID-19, está provocando que se utilicen los medios policiales para controlar a la población, ya sea manteniendo a los individuos recluidos en sus hogares, ya sea obligándolos a utilizar mecanismos de protección.

En España, siguiendo el ejemplo de otros países del mundo, han proliferado varias técnicas de búsqueda y detección de casos de personas infectadas, por medio de los llamados "rastreadores", los cuales pueden pertenecer o no a las fuerzas y cuerpos de seguridad del Estado, por lo que dicha categoría puede ser ejercida por individuos investidos como "rastreador" ad hoc, sin ni siquiera requerirse una formación específica. De la misma manera, el Estado y los gobiernos de las distintas regiones del territorio español, están haciendo uso de aplicaciones móviles para la detección y rastreo del virus -denominada APP Radar COVID-, la cual -como es evidente- además de controlar los casos de tal enfermedad, en virtud de las localizaciones del móvil a las que accede -mediante los correspondientes permisos y cookies, los cuales necesariamente el usuario debe aceptar-, puede conocer el lugar por el que transita una persona, sus contactos, sus lugares frecuentados con habitualidad, su hogar, su lugar de trabajo, por

51 Téngase en cuenta, aparte de esta posibilidad, la vigilancia constante de redes sociales, de internet, de nuestras comunicaciones que quedan grabadas, y que son usadas por los Cuerpos y Fuerzas de Seguridad y por los servicios de inteligencia.

52 La actual sociedad abierta, la sociedad moderna, crea un fuerte sentido de pertenencia entre los miembros del grupo sin embargo, este apego favorece a su vez la coerción de aquellos que pueden ejercer el poder frente a los otros grupos o colectivos, los cuales son excluidos (Ignatieff, 2018, p. 329). Algo así, puede explicar los recientes ataques policiales que asolan a Estados Unidos, y la violencia racial que se está produciendo en los últimos meses recurrentemente contra la población afroamericana, tales como la muerte de Jacob Blake, Ahmaud Arbery o George Floyd. Esta situación no es para nada novedosa, ya que hace un cuarto de siglo los gobiernos de Bill Clinton mediante la reforma de la salud y otras medidas de su gobierno, con el pretexto de eliminar la dependencia de parte de la población estadounidense a las ayudas públicas, suprimieron algunas de ellas, con el claro objetivo de contentar al electorado amplio y acercar al crimen a las clases desfavorecidas, compuestas por afroamericanos e hispanos, propendiendo y favoreciendo la ociosidad, el desempleo, la a-socialización y el establecimiento de marcos de criminalidad en estos grupos sociales, que se consideran marginales y viles por parte del amplio grueso de la sociedad (Wacquant, 2009, pp. 76-85). 
lo que el coronavirus a la postre, será una mera argucia para menoscabar las libertades y derechos individuales de los hombres y mujeres del mundo, consolidando -si es que ya no lo estaba- a las sociedades de control -en la actualidad- global.

\section{Conclusiones}

El artículo ha explicado cómo el ser humano en sociedad ha creado una serie de sistemas para garantizar la seguridad de sus miembros, mediante mecanismos de control social.

Uno de estos mecanismos consistió en la utilización de un castigo al individuo que contravenía las normas de conducta impuestas por dicha sociedad. Sin embargo, la pena impuesta como sanción fue variando al transcurrir de los siglos, surgiendo incluso una rama jurídica encargada de normalizar el derecho a castigar del Estado -ius puniendi-, y tipificar las conductas consideradas lo suficientemente graves como para merecer un reproche penal.

Esa fue la época en la que el castigo corporal y los suplicios fueron dejando paso a la pena de privación de libertad, lo que requirió de un lugar concreto para ejecutar tal sanción penal y generó -por consiguiente, ante la aparición del liberalismo y el utilitarismo- la instauración de las denominadas sociedades de control, basadas principalmente en la vigilancia y la disciplina.

Estas sociedades -de control- aún vigentes, no han abandonado la vida contemporánea, sino que a pesar de los enormes problemas generados en el ejemplo paradigmático de las mismas -esto es, en las cárceles- a la hora de ejecutar las penas de prisión -lo que llevó a las tesis más humanizadoras y resocializadoras de la pena-, continúan utilizándose, habiendo estas evolucionado en sociedades que pretenden neutralizar los "eventuales" peligros, mediante los procesos de inocuización de aquellos sujetos que atentan contra los valores y bienes fundamentales del género humano; pero -simultánea y paralelamente- también se ataca los derechos ampliamente reconocidos y fundamentales de los individuos, mediante los procedimientos de abolición de cualquier riesgo -al menos de una manera simbólica y/o mediática-; ahora bien -como se viene diciendo-, a costa de confinar a espacios mínimos las esferas individuales de libertad, que -en esta línea- tenderán a desaparecer.

\section{Referencias bibliográficas}

Baratta, A. (1999). Reintegración Social del detenido. Redefinición de concepto y elementos de operacionalización. La pena, Garantismo y Democracia. Santa Fe de Bogotá: Ediciones Jurídicas. 
Beccaria, C. (1828). Tratado de los Delitosy de las Penas. París: En Casa de Rosa -Librero-.

Benezic, D. (30 de diciembre de 2016). Un tour por Halden, la cárcel más humana del mundo. Liberties. Recuperado de https://www.liberties.eu/es/news/haldenla-carcel-mas-humana-del-mundo/11078

Bentham, J. (1839). Compendio de los Tratados de Legislación civil y penal. Madrid: Librería de la Viuda de Calleja e Hijos.

Botella Soria, E.N. (2010). La reforma del Código Penal de 2010 en materia de tráfico de drogas y la aplicación retroactiva de la ley más favorable. La Ley Penal: revista de derecho penal, procesal y penitenciario, (76).

Bruno, C. (octubre de 2006). Evolución histórica de las construcciones penales en Argentina. Congreso de Arquitectura Penitenciaria.

Caro Pozo, F. (2013). John Howard y su influencia en la reforma carcelaria europea de finales del Siglo XVIII. Eguzkilore: Cuaderno del Instituto Vasco de Criminología, (27), 149-168.

Cesano, J.D. (2017). Prólogo. En García Basalo, A. (ed.), Para seguridad y no para castigo. Origen y evolución de la arquitectura penitenciaria provincial argentina (18531922) (pp. 9-14). San Miguel de Tucumán: Universidad Nacional de Tucumán e Instituto de Investigaciones Históricas Leoni Pinto.

Cuello Calón, E. (1968). La moderna penalogía. Barcelona: Bosch.

Daunis Rodríguez, A. (2016). Ocupación carcelaria. Hipótesis acerca del descenso de la población penitenciaria en España. Estudios Penales y Criminológicos, 36. Recuperado de https://revistas.usc.es/index.php/epc/article/view/3359

J. De J. (2017). El neandertal cojo, sordo y manco que llegó a viejo por "compasión". Diario ABC. Recuperado de https://www.abc.es/ciencia/abci-neandertal-cojosordo-y-manco-llego-viejo-compasion-201710251131_noticia.html

Elbert, C.A. (2001). Manual básico de Criminología. Buenos Aires: Eudeba.

Estrada Cuzcano, A. (2005). Internet: cambio social, libertad e intimidad. Escritura y Pensamiento, 8(16), 149-162

Ferrajoli, L. (1998). Derecho y razón. Teoría del garantismo penal. Madrid; Trotta.

Foucault, M. (1990). Vigilar y castigar. Madrid: Siglo XXI Editores.

Fraile, P. (1987). Un espacio para castigar. La cárcel y la ciencia penitenciaria en España (siglos XVIII-XIX). Barcelona: Ediciones del Serbal.

Franco, G. (1962). Las leyes de Hammurabi: versión española, introducción y anotaciones. Revista de Ciencias Sociales, 6(3), 331-356.

García Basalo, A. (2003). Complejos penitenciarios. Alcance de la relación entre arquitectura y régimen penitenciario. Revista de Estudios Criminológicosy Penitenciarios, (6), 59-91.

García Basalo, A. (2018). La arquitectura penitenciaria de cuarta generación. ¿Pueden ser más humanas las prisiones. Revista Electrónica de Estudios Penales y de la Seguridad, (3). 
Garland, D. (1999). Castigo y sociedad moderna. Un estudio de teoría social. Madrid: Siglo XXI Editores.

Garland, D. (2005). La cultura del control. Crimen y orden social en la sociedad contemporánea. Barcelona: Editorial Gedisa.

Ginzburg, C. (2015). Miedo, reverencia, terror: releer a Hobbes hoy. Apuntes de Investigación del CECYP, (26), 30-49.

Ignatieff, M. (2018). Conclusions: The Future of the Open Society Ideal. In Ignatieff, M. \& Roch, S. (eds.), Rethinking Open Society. New adversaries and New Opportunities (pp. X-x). Budapest: Central European University Press.

James, E. (25 de febrero de 2013). The Norwegian prison where inmates are treated like people. The Guardian. Recuperado de https://www.theguardian.com/ society/2013/feb/25/norwegian-prison-inmates-treated-like-people

Jiménez de Asúa, L. (1957). Concepto del Derecho Penal y de la Criminología, Historia y Legislación Penal Comparada. En Tratado de Derecho penal (Tomo I). Buenos Aires: Losada.

Lalinde Abadía, J. (1992). Las culturas represivas de la humanidad. Zaragoza: Universidad de Zaragoza.

Lamet, J. (25 de febrero de 2019). El PP propone castigar la rebelión con la prisión permanente. El Mundo. Recuperado de https://www.elmundo.es/espana/20 19/02/25/5c72efc321efa0224f8b46c8.html

Lewis, J. (2009). Una prisión de la que nadie quiere escapar. Etiqueta Negra, (18).

López, M.A. (1832). Descripción de los más célebres establecimientos penales de Europa y los Estados Unidos. Valencia: Imprenta de Don Benito Monfort.

Magallanes Maldonado, M.M. (2002). La inocuización. Frente a los delincuentes sexuales peligrosos, incorregibles, reincidentes. Revista Jurídica Cajamarca, (7).

Malo Camacho, G. (2001). Derecho Penal Mexicano. México, D. F.: Editorial Porrúa.

Mapelli Caffarena, B. (2006). Una nueva versión de las normas penitenciarias europeas. Reflexiones, Revista Electrónica de Ciencia Penal y Criminología, (8), 1-44.

Margariños, N. (2008). Arquitectura y construcción de prisiones: Nuevas cárceles, viejos problemas. Encrucijadas, (43).

Melossi, D. (1980). Las estrategias de control social en el capitalismo. Papers: Revista de Sociología, (13), 165-196.

Melossi, D. (2015). Crime, punishment and migration. Londres: SAGE Publications.

Melossi, D. (2018). Controlar el delito, controlar la sociedad: Teorías y debates sobre la cuestión criminal, del siglo XVIII al siglo XXI. Buenos Aires: Siglo XXI Editores.

Melossi, D. y Pavarini, M. (2010). Cárcel y fábrica. Los orígenes del sistema penitenciario (siglos XVI-XIX). México D.F.: Siglo XXI Editores. 
Montesquieu. (1972). Del espíritu de las leyes. Madrid: Tecnos.

Moreno Catena, V. y Cortés Domínguez, V. (2017). Introducción al Derecho procesal. Valencia: Tirant lo Blanch.

Nieves, J.M. (2014). Los neandertales sí eran buenos padres. Diario ABC. Recuperado de https://www.abc.es/ciencia/20140410/abci-dura-infancia-ninos-neandertal-201404101000.html

Paiva, M.A. (1966). Programa de Ordenamiento y Transformación en la Dirección General de Institutos Penales, año 1967. Revista Penal y Penitenciaria, (27), 5-62.

Pérez Tolentino, J.A. (2012). La inocuización como prevención especial negativa. Archivos de Criminología, Criminalística y Seguridad Privada, 8, 1-6.

Ramírez, A. (2011). Thomas Hobbes. El carácter pasional de lo humano: la primacía de lo individual y la dimensión subjetiva del "considerar". In Itinere. Revista Digital de Estudios Humanísticos de la Universidad FASTA, 1(1).

Rothman, D.J. (1998). Perfecting the Prison: United Sates, 1789-1865. In Morris, N. \& Rothman, D.J. (eds.), The Oxford History of the Prison. The Practice of Punishment in Western Society (pp. x-x). Oxford: Oxford University Press.

Rusche, G. y Kirchheimer, O. (1984). Pena y Estructura social. Bogotá: Temis.

Ruiz Funes, M. (1949). La crisis de la prisión. La Habana: Montero.

Ruiz-Morales, M.L. (2018a). Corruptelas y prácticas ilícitas en la Antigüedad: soluciones análogas a las actuales en la historia del pensamiento. Foro, Nueva Época, 21(1), 303-327.

Ruiz-Morales, M.L. (2018b). El castigo en prisión: la cárcel como resultado del entendimiento del castigo. En Irrazabal, G. (coord.), Gestión de la inseguridad, violencias y sistema penal (pp. 37-62). Temperley: Tren en Movimiento.

Ruiz-Morales, M.L. (2018c). Medios de comunicación y corrupción. ¿Tipificación conforme al entendimiento social?. En Rodríguez García, N., Carrizo González-Castell, A. y Leturia Infante, F. (dirs.), Justicia penal pública y medios de comunicación (pp. 631-655). Valencia: Tirant lo Blanch.

Ruiz Rodríguez, L.R. (2006). Sistema penal y exclusión de extranjeros. Albacete: Bomarzo.

Silva Sánchez, J. M. (2001). “El retorno de la inocuización”. En Arroyo Zapatero, L. y Berdugo Gómez de la Torre, I. (coords.), Homenaje al dr. Marino Barbero Santos "in memoriam" (pp. 699-710). Salamanca: Universidad de Salamanca.

Sozzo, M. (2009). Populismo punitivo, proyecto normalizador y “prisión-depósito" en Argentina. Sistema Penal \& Violência, 1(1), 33-65.

Téllez Aguilera, A. (1996). La crisis de la prisión: aproximación práctica a las nuevas fórmulas penológicas. Anuario de la Facultad de Derecho, (6), 99-136.

Tinedo Fernández, G. (2008). Reflexiones sobre el sentido de la pena. Capítulo criminológico: revista de las disciplinas del Control Social, 36(4), 27-50. 
Todarello, G.A. (2008). Corrupción administrativa y enriquecimiento ilícito. Buenos Aires: Editores del Puerto.

Tomás y Valiente, F. (1973). La tortura en España. Barcelona: Ariel.

Vega Fernández, E. (2017). El control y la prevención del delito como objeto de la criminología. Miscelánea Comillas, 75(146).

Vitale, G.L. (2007). Encarcelamiento de presuntos inocentes: hacia la abolición de una barbarie. Buenos Aires: Hammurabi.

von Liszt, F. (1905). Der Zweckgedake im Strafrecht (Maurburger Programm), 1982. In Strafrechtliche Ausfsätze und Vorträge. Berlín: J. Guttentag Verlagsbuchhandlung.

Wacquant, L. (2004). Las cárceles de la miseria. Buenos Aires: Manantial.

Wacquant, L. (2009). Punishing the Poor. The Neoliberal Government of Social Insecurity. Durham: Duke University Press.

Zaffaroni, E.R. (1993). Hacia un realismo jurídico penal marginal. Caracas: Monte Ávila Editores.

Zaffaroni, E.R. (1997). La Filosofía del Sistema Penitenciario en el Mundo Contemporáneo. Themis, Revista de Derecho, (35), 179-191.

Zambrana Moral, P. (2005). Rasgos generales de la evolución histórica de la tipología de las penas corporales. Revista de Estudios Histórico-Jurídicos, (27), 197-229

Zambrana Moral, P. (2010). Tipologías de penas corporales medievales. Quadernos de Criminología, (11), 6-12.

Zipf, H. (1979). Introducción a la Política Criminal. Madrid: Edersa.

Zuleta, G. (16 de enero de 2011). Ganador del Concurso para la Prisión Danesa en Falster / C. F. Møller. Plataforma Arquitectura. Recuperado de http://www. plataformaarquitectura.cl/cl/02-69746/ganador-del-concurso-para-laprision-danesa-en-falster-c-f-m\%25c3\%25b8ller 